\title{
Respiratory failure in acute pancreatitis
}

\author{
AK Banerjee, SJ Haggie, RB Jones, GS Basran
}

\begin{abstract}
Summary
There are a number of important pulmonary complications of acute pancreatitis which make a significant contribution to the morbidity and mortality of the condition. The pathophysiology and management guidelines are given for each and approaches towards better treatment in the future are discussed.
\end{abstract}

Keywords: acute pancreatitis, respiratory failure, neutrophils

\begin{tabular}{|l|}
\hline Pulmonary complications \\
of acute pancreatitis \\
\hline - pleural effusion \\
- pulmonary infarction \\
- elevated diaphragm \\
- atelectasis \\
- pneumonia \\
- empyema \\
\hline
\end{tabular}

Box 1

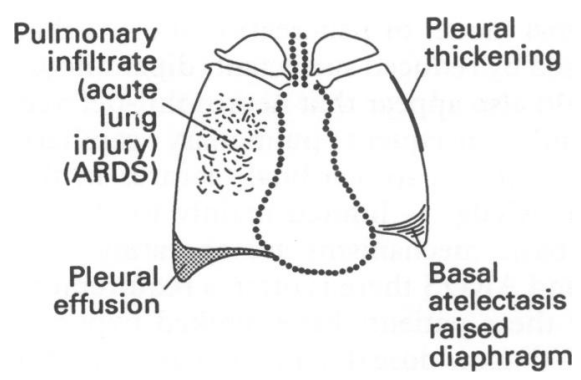

Figure 1 Radiological abnormalities in acute pancreatitis

Rotherham District General Hospital, Moorgate Road, Rotherham S60 2UD, UK

Department of Surgery

AK Banerjee

SJ Haggie

RB Jones

Department of Respiratory Medicine GS Basran

Correspondence to Mr AK Banerjee, Flat 1, 51 Botanical Road, Sheffield S11 8RP, UK

Accepted 31 January 1995
Acute pancreatitis remains a major and costly cause of morbidity and mortality in the UK. ${ }^{1}$ It affects all age groups and its incidence is increasing. Sixty per cent of deaths from acute pancreatitis occur within the first week of illness and are associated with acute respiratory failure. ${ }^{2}$

A number of pulmonary complications may be seen in patients with acute pancreatitis (see box 1 and figure 1). This paper will deal with recent advances which improve our understanding of the mechanisms and potentially therapeutic strategies of each of these.

\section{Pleural effusion}

A high concentration of amylase and lipase may be found in pleural effusion fluid either due to exudative leak or by passage via transdiaphragmatic lymphatic channels. ${ }^{3}$ To distinguish benign causes of amylase-rich effusions from other aetiologies (including carcinoma, lymphoma, and leukaemia), analysis of isoenzymes may prove useful. ${ }^{4}$ In pancreatitis, the isoenzyme is pancreatic whilst in many of the other situations, including neoplasia, it is salivary. ${ }^{5}$ The values of pleural fluid amylase are highest in patients with pancreatitis, although there is considerable overlap. Thirteen per cent of consecutive cases of pleural effusion of any origin in Rotherham had elevated amylase content and of these only $16 \%$ had pancreatitis. ${ }^{4}$ The pathogenesis of an amylase-rich effusion in pancreatitis includes lymphatic passage or seepage of the enzyme across the diaphragm, direct transdiaphragmatic movement via a congenital defect, or passage through a fistulous track through the mediastinum, opening into the pleural cavity. ${ }^{6}$ Other potential mechanisms include haematogenous transfer of amylase to the pleural space, transfer through congenital hiatal remnants and diaphragmatic perforation by a pancreatic pseudocyst. ${ }^{7}$ Investigation of the pleural effusion kinetics in pancreatitis has shown that fluid formation is associated with increases in microvascular permeability, resulting in a leak of fluid with high concentrations of amylase. ${ }^{8}$

The management of this condition essentially involves pleural tap if the effusion is symptomatic, otherwise spontaneous resolution will follow control of the underlying pancreatitis.

\section{Atelectasis/elevated diaphragms}

Pulmonary atelectasis in pancreatitis may be secondary to the loss of forces opposing retraction of the lung. This may be secondary to ascites raising the diaphragm or empyema, effusion or haemothorax in the pleural cavity causing secondary lung collapse. Absorption collapse can occur in the absence of total airway obstruction provided that the ventilation/perfusion $(\mathrm{V} / \mathrm{Q})$ ratio is sufficiently reduced. Patients with acute pancreatitis and pulmonary oedema may have substantial perfusion of areas of lung with $V / Q$ ratios in the range $0.01-0.1$. These grossly hypoventilated areas are liable to collapse if the patient breathes oxygen. Recent work in a rat model of whole lung atelectasis in which the left main stem bronchus was ligated while maintaining ventilation of the right lung, showed that both interleukin-1 and tumour necrosis factor levels of macrophage cultures from the atelectatic lung were significantly increased compared with the control lung. ${ }^{9}$ These mechanisms could be responsible for some of the systemic effects seen in severe acute pancreatitis, but further evidence is needed.

In patients who are spontaneously breathing, satisfactory oxygenation can be achieved by continuous positive-airways pressure (CPAP) of between 5 and $10 \mathrm{~cm} \mathrm{H}_{2} \mathrm{O}$.

The patient breathes spontaneously through an endotracheal tube or tightly fitting face mask and an oxygen-air mixture is delivered at high flow $(>70 \mathrm{l})$ $\mathrm{min}$ ). CPAP re-expands collapsed alveoli, increasing functional residual capacity and lung compliance, such that the work of breathing is reduced and gas exchange is improved. 


\section{Pulmonary infarction}

Pulmonary emboli are more common in acute pancreatitis, sometimes producing sudden death but more commonly causing peripheral pulmonary infarction. Peripheral pulmonary thrombosis may be a more common but less well recognised factor. Recent work would appear to show that local pulmonary platelet activating factor occurs in acute pancreatitis which results in localised infarction. ${ }^{10}$ This in turn may be due to accumulation of plasma phospholipase A2. Certainly, pulmonary tissue concentrations of platelet activating factor are increased in experimental pancreatitis and correlate with the progression of lung injury. ${ }^{11}$ In a separate study, the pulmonary microvasculature was examined in both the taurocholate and caerulein rat models of acute pancreatitis by scanning electron microscopy of microvascular corrosion casts. ${ }^{12}$ In mild pancreatitis abruptly terminating vessels were present. In more severe pancreatitis, there was substantial loss of vascular density, tortuosity, and abrupt terminations of those vessels present. It has therefore been suggested that microvascular abnormalities may be responsible for some of the pulmonary changes seen in oedematous and haemorrhagic pancreatitis, and in particular pulmonary infarction. ${ }^{12}$

Management of this condition can be difficult but would include antibiotics to cover infection of the infarct and consideration of anticoagulation, although this may precipitate haemorrhagic pancreatitis.

\section{Pneumonia/empyema}

There are several mechanisms by which this could occur. A localised area of infarction or pleural effusion could become secondarily infected. Generalised sepsis and multiple organ failure is seen and is discussed more fully under adult respiratory distress syndrome below. Increased intestinal permeability may allow absorption of toxins and bacteria into the systemic circulation which may permit a blood-borne septic episode in the lung. Neutrophil activation is a significant event in acute pancreatitis; the activated neutrophil possesses properties that promote its adhesiveness to vascular endothelium which may lead to increased susceptibility to pyogenic organisms. ${ }^{13}$

Treatment consists of respiratory support, hydration, and broad spectrum antibiotics. Empyema may require transcutaneous drainage under ultrasound guidance: open surgical drainage is rarely needed.

\section{Adult respiratory distress syndrome}

The most significant pulmonary side-effect is pulmonary hypoxia which may manifest itself as acute lung injury which, in its most severe form, is termed adult respiratory distress syndrome (ARDS). This latter condition is characterised by lung stiffness, pulmonary oedema, and endothelial damage. The pathogenesis is unclear. Recent work in a caerulein animal model of pancreatitis showed that lung injury in this condition is characterised by reduced surfactant (dipalmitoylphosphatidyl choline) synthesis. ${ }^{14}$ It would also appear that neutrophil-derived generation of oxygen free radicals and consequent pulmonary capillary endothelial cell membrane permeability increase are cardinal features in the development of the lesion. ${ }^{15}$ In man, knowledge is limited mainly to clinical experience but it is likely that similar basic mechanisms are operating. ${ }^{16}$ In patients developing pulmonary oedema and ARDS there is often a requirement for intravenous colloid and additionally these patients have marked hypocalcaemia and often hypertriglyceridaemia. ${ }^{17-20}$ Low dose dopamine may be useful in preventing ARDS, perhaps by acting on neutrophil-derived oxygen free radicals but further clinical evidence is required. ${ }^{21}$

What should the clinician do when confronted by this potentially lifethreatening problem? The first priority must be to suspect a clinical diagnosis of pancreatitis. In a retrospective series of patients with fatal acute pancreatitis from Glasgow, nearly $40 \%$ of cases were first recognised at post mortem. ${ }^{17}$ Once diagnosed, arterial blood gases are an essential step to determine a predicted severe attack. In another study from the same centre, severe arterial hypoxia while breathing ambient air $\left(\mathrm{PaO}_{2}<8.0 \mathrm{kPa}\right)$ was recorded in $38(45 \%)$ of a group of 84 patients during the first week of admission. Clinical evidence of respiratory failure was rarely present and yet the hypoxia was an adverse prognostic indicator of outcome. ${ }^{18}$ The study concluded that all older patients (over 60 years) with acute pancreatitis and all younger patients with moderate hypoxia $\left(\mathrm{PaO}_{2}<10 \mathrm{kPa}\right)$ should be given supplementary humidified oxygen. All patients should have arterial blood gases determined on admission and those with moderate hypoxia or in a predicted high-risk group for severe attack based upon APACHE II criteria should have blood gases performed serially thereafter. 


\section{Respiratory support: newer approaches}

- inverse ratio ventilation

- high frequency jet ventilation

- permissive hypercapnia

- extracorporeal membrane oxidation

\section{Box 3}

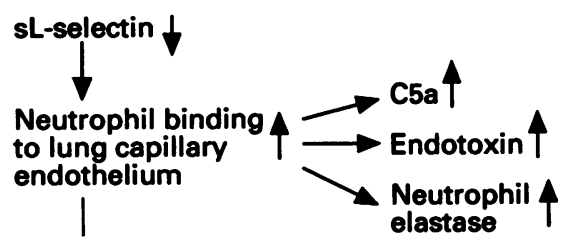

IL-8 from lung 4

macrophages

Figure 2 Role of selectins in pathogenesis of ARDS

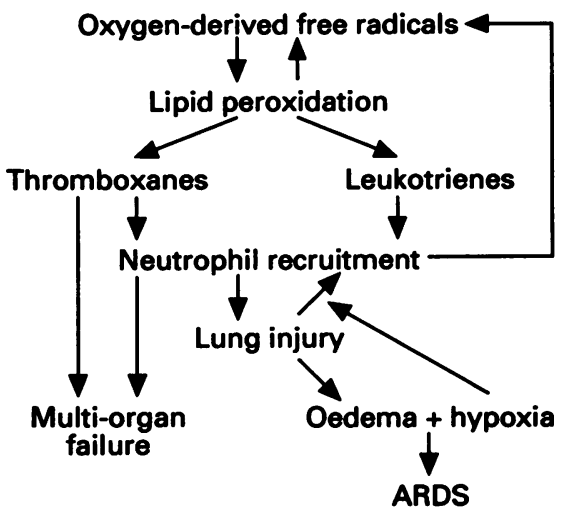

Figure 3 Role of inflammatory mediators in pathogenesis of ARDS

\begin{tabular}{|l|}
\hline Summary/learning points \\
\hline - amylase isoenzyme analysis can \\
help to differentiate causes of \\
pleural effusion in acute \\
pancreatitis \\
- CPAP may be helpful in \\
management of atelectasis \\
- hypoxia is a poor prognostic sign in \\
acute pancreatitis \\
- early transfer to high dependency \\
units is to be encouraged \\
- specific therapy for ARDS in \\
pancreatitis will depend on better \\
understanding of cytokines and \\
selectins in pathophysiology
\end{tabular}

Box 4

When respiratory failure is imminent, patients should be transferred to a high dependency or intensive care facility for monitoring and ventilation as needed.

\section{TREATMENT}

Treatment of patients with acute pancreatitis and ARDS remains supportive and aims to maintain oxygen delivery to all organ systems, as most patients with ARDS usually die from multiple organ failure. ${ }^{22,23}$

Respiratory support includes standard controlled mandatory mechanical ventilation or synchronised intermittent mandatory ventilation. The synchronised technique allows the patient to initiate preset ventilator breaths whilst permitting spontaneous ventilation in between. However, conventional methods of ventilation which expose the lung to high peak airway pressures may exacerbate lung injury. Newer approaches are listed in box 3. Fluid balance and renal support may include diuretics and fluid restriction provided that cardiac output and oxygen delivery is maintained. Cardiac output may be compromised in ARDS by several mechanisms including low filling pressures secondary to fluid restriction, high levels of CPAP or positive end expiratory pressure and increased pulmonary vascular resistance. Myocardial function may be further compromised by circulating inflammatory mediators, especially in sepsis. Inotropes, such as dobutamine, are often required to maintain oxygen delivery. Sepsis may be treated with broad spectrum antibiotics: there is evidence that enteral is associated with fewer septic complications than parenteral nutrition.

\section{Future development}

The main area for research is the basic biological derangements that lead to the conversion of a local disorder of the pancreas into a multisystem and potentially fatal condition. Clues can be obtained from animal model work and studies on surgical septic shock. ${ }^{15,24}$ Pulmonary white cell trapping and activation are probably important: increases in intestinal and pulmonary permeability might explain endotoxaemia caused by the gut flora which may flourish relatively unchecked because of white cell trapping. ${ }^{25}$ Elegant studies have shown the pulmonary microvascular permeability, as measured by transferrin, to be increased in ARDS in patients with acute pancreatitis, ${ }^{26-30}$ although a trial of therapy with methylprednisolone in this condition proved inconclusive. ${ }^{31}$ Recent work has shown the importance of selectins and cytokines in the pathogenesis of ARDS in general and that altered neutrophil adhesion may be related to an adverse outcome $\mathrm{e}^{32,33}$; specific research is currently being performed to investigate similar mechanisms in severe pancreatitis (figures 2 and 3 ). Therapy could then be designed to target both these defects and the consequent increase in neutrophil-derived oxygen free radicals. On an experimental level, recent work has raised the possibility of cytokine antagonists. This may be using agents that compete for receptor sites such as the protein antagonists Interleukin-1 ra (IL-1 ra) or monoclonal antibodies to tumour necrosis factor alpha and its soluble receptor. Another approach is to decrease monocyte production of cytokines by cytokine-suppressing anti-inflammatory drugs which inhibit a specific tyrosine kinase, cytokine suppressing binding protein. ${ }^{34}$ In the mean time, the emphasis should be focused on a wider diagnostic awareness of this condition and close clinical vigilance with a low threshold for ventilatory support and intensive care monitoring before irreversible deterioration of the patient occurs.

\section{Conclusions}

There are a wide variety of pleuropulmonary complications of acute pancreatitis. The pathophysiology of these have been better understood with recent cell and molecular biological research techniques but the treatment remains largely empirical and supportive. It is important for the respiratory physician to be aware of the range of disorders since, not uncommonly, they may even be the presenting features of this potentially life-threatening condition.

AKB is in receipt of grants from Trent Regional Health Authority and from the Fellowship of Postgraduate Medicine to investigate the mechanism of respiratory failure in acute pancreatitis.

4 Joseph J, Viney S, Beck P, Strange C, Sahn SA, Basran GS. A prospective study of amylase rich pleural effusions with special reference to amylase isoenzyme analysis. Chest 1992; 102 $1455-9$.

5 Goldman M, Goldman G, Fleischner FG. Pleural fluid amylase in acute pancreatitis $N$ Engl fु Med 1962; 266: 715.
6 Cameron JL. Chronic pancreatic ascites and pancreatic pleural effusions. Gastroenterology 1978; 74: 134-40.

7 Kaye MD. Pleuropulmonary complications of pancreatitis. Thorax 1968; 23: 297-306.
Roseman DM, Kowlessar OD, Sleisenger MH Pulmonary manifestations of pancreatitis. $N$ Engl f Med 1960; 263: 294-6.

1 Carter DC. Acute pancreatitis: the value of life. Br F Surg 1993; 80: 1499-1500. Renner IG, Savage WT, Pantoja JL, Renner VJ. Death due to acute pancreatitis: a retrospective 
8 Joseph J, Smith MJ, Flatman WD, Basran GS $A$ study of pleural effusion formation and drainage in man using a dual isotope technique. Nucl Med Commun 1990; 3: 180-1.

9 Kisala JM, Ayala A, Stephan RN, Chaudry IH. A model of pulmonary atelectasis in rats: activation of alveolar macrophage and cytokine release. Am ₹ Physiol 1993; 264: 610-4.

10 Zhou W, McCollum MO, Levine BA, Olson MS. Role of platelet activating factor in pancMS. Role Am $\Im$ Pathol 1992; 140: 971-9.

11 Formela LJ, Wood LM, Whittaker M, KingFormela LJ, Wood LM, Whittaker $M$, Kingsnorth AN. Amelioration of experimental acute pancreatitis with a potent platelet activating Kelly DM, McEntee GP, McGeeney KF, Fitzpatrick JM. Pulmonary microvasculature in expatrick JM. Pulmonary microvasculature in experimental acute haemorrhagic and oedema
pancreatitis. Br f Surg 1991; 78: 1064-7.

13 Rinderknecht H. Fatal pancreatitis, a consequence of excessive leukocyte stimulation? Int $f$ Pancreatol 1988; 3: 105-12.

14 Guice KS, Oldham KT, Wolfe RR, Simmons RH. Lung injury in acute pancreatitis: primary inhibition of pulmonary phospholipid synthesis. Am ₹ Surg 1987; 153: 54-61.

15 Guice KS, Oldham KT, Johnson KJ, Kunkel RG, Morganroth ML, Ward PA. Pancreatitis induced acute lung injury. Ann Surg 1988; 208: 71-7.

16 Warshaw AL, Lesser PB, Rie M, Cullen JS. The pathogenesis of pulmonary edema in acute pancreatitis. Ann Surg 1975; 182: 505-10.
17 Wilson C, Imrie CW, Carter DC. Fatal acute pancreatitis. Gut 1988; 29: 782-8.

18 Imrie CW, Ferguson JC, Murphy D, Blumgar LH. Arterial hypoxia in acute pancreatitis. $\mathrm{Br} \mathcal{J}$ Surg 1977; 64: 185-8.

19 Lankisch PG, Rahlf G, Koop H. Pulmonary complications in fatal acute haemorrhagic pancreatitis. Dig Dis Sci 1983; 28: 111-6.

20 Ranson JHC, Roses DF, Fink SD. Early respiratory insufficiency in acute pancreatitis. Ann piratory insuficiency in
Surg 1973; 1978: 75-9.

21 Karanjia ND, Widdison AL, Lutrin FJ, Reber HA. Dopamine in models of alcoholic acute pancreatitis. Gut 1994; 35: 547-51.

22 MacNaughton PD, Evans TW. Management of adult respiratory distress syndrome. Lancet adult respiratory

23 Rocker GM, Wiseman MS, Pearson D, Shale DJ. Diagnostic criteria for ARDS: time for reappraisal. Lancet 1989; i: 120-3.

24 Guillou PJ. Biological variation in the development of sepsis after surgery or trauma. Lancet 1993; 342: 217-20.

25 Banerjee AK, Galloway SW, Kingsnorth AN Experimental models of acute pancreatitis. $\mathrm{Br} \mathscr{F}$ Surg 1994; 81: 1096-103.

26 Basran GS. Ramasubramanian R, Verma $R$ Intrathoracic complications of acute pancreatitis. $B r \mathcal{F}$ Dis Chest 1987; 81: 326-31.

27 Basran GS, Hardy JG. Monitoring pulmonary vascular permeability using radiolabelled transvascular permeability using radiolabelled t
28 Robertson CS, Basran GS, Hardy JG. Lung vascular permeability in patients with acute pancreatitis. Pancreas 1988; 3: 162-5.

29 Rocker GM, Pearson D, Stephens M, Shale DJ. An assessment of a double isotope method for the detection of transferrin accumulation in the lungs of patients with widespread pulmonary infiltrates. Clin Sci 1988; 75: 47-52.

30 Wilkinson MJ, Robson DK, Basran GS. Pleural complications of acute pancreatitis - an autopsy complications of acute pancreatitis - an

31 Basran GS, Byrne AJ, Hardy JG, Richardson BA. pA. The effect of methylprednisolone on the pulmonary accumulation of transferrin in the pir Dis 1986; 68: 336-41.

32 Donnelly SC, Streiter RM, Kunkel SL, et al. Interleukin-8 and development of adult respiratory distress syndrome in at-risk patien groups. Lancet 1993; 341: 643-7.

33 Donnelly SC, Haslett C, Dransfield I, et al. Role of selectins in development of adult respirator distress syndrome. Lancet 1994; 344: 215-9.

34 Lee JC, Laydon JT, McDonnell PC, et al. A protein kinase involved in the regulation of inflammatory cytokine biosynthesis. Nature 1994; 372: 739-46.

\section{EUROPEAN DOCTORS IN LONDON}

European Medical Research Group

The European Medical Research Group has been formed by the European Association of Internal Medicine with the support of the Fellowship of Postgraduate Medicine, to provide a meeting place for professional and social contact among physicians in training, particularly those from continental Europe. Regular meetings are held at the Medical Society of London. An invited lecture is given, preceded by poster presentations and followed by a buffet supper.

Members of the Group are mailed regularly about the meetings. Next meeting: Wednesday 12 July 1995. Speaker: Professor Lucilla Poston.

European research fellows and other visiting doctors who would like details of these meetings should write to:

Dr DRJ Singer, c/o The Fellowship of Postgraduate Medicine, 12 Chandos Street, London W1M 9DE. Tel: 01716366334 